\title{
Cognitive aspect of studying the terminology of clinical psychology
}

\author{
T. I. Semykras
}

Taras Shevchenko National University of Kyiv, Ukraine

Corresponding author. E-mail: semykras.t@gmail.com

Paper received 25.01.18; Revised 28.01.18; Accepted for publication 29.01.18.

https://doi.org/10.31174/SEND-Ph2018-151VI44-13

Abstract. The study examines the definition of the term in the scientific literature; the relation of the term to the concept and word is analyzed; the main functions of the term are indicated; modern approaches to studying the terminology are applied. The article contains the analysis of the terms of clinical psychology.

Keywords: term, terminology, clinical psychology, eponym, mythologizm.

Introduction. The description and analysis of scientific and technical terminology have been the leading directions of linguistic research over recent decades. The growing interest towards the issues of special nominations is due to the increasing role of terminology and its standardization in various fields of knowledge. With the aim of achieving a single designation and understanding the essence and processes of the surrounding world, and in order to obtain maximum efficiency from the activities of specialists in various fields of science and production, the questions of unification and harmonization of terminology are being raised. The process of ordering the scientific and technical space largely depends on overcoming linguistic disunity in the professional fields of knowledge, therefore nowadays in the field of linguistics, those kinds of research that are aimed at overcoming language barriers in professional fields are of paramount importance. Terminologists and linguists study both the process of term formation as well as its fixing in the terminology system; they also identify the main nomination mechanisms that carry out purposeful activities to achieve the equivalence of the translation of terminological vocabulary and to establish correct interlanguage correspondences of terminological concepts at the national and international levels. An important role in terminological research plays medical terminology, which has been shaping for centuries and continues to develop dynamically. The uninterrupted interest in medical terminology leads to the emergence of a large number of works devoted to various aspects of its study (M.N. Chernyavskyy (1984), L. Tatarinova (1984), G. G. Yeromkina (1991), E.V. Bekishev (1998 ), L.F. Eltsova (2000), S.L. Mishlanova (2002), L.N. Gushchina (2004), Z.P. Palyutina (2005), E.V. Bekishev (2007), S.G. Dudetska (2007), T.A. Trafimenkova (2008), A.V. Velichko (2010) M.V. Ozingin (2010) E.M. Kakzanova (2011), etc.). The obtained evidence makes it possible to consider medical terminology as an autonomous section of general terminology, and it also equips linguists with valuable information about the organization of the internal structure of the language.

The relevance of the study is determined by the importance of the topic for the general linguistic studies that are based on detailed research of individual terminology systems, which allows us to establish the modern features of their system-structural organization and dynamic characteristics. The wide dissemination of knowledge, the internationalization of scientific research and other factors of social development require a comprehensive and indepth study of the mechanisms of nominating in the modern terminology, as well as its compositional and semantic characteristics. However, the part of medical terminology related specifically to clinical psychology is not fully described in modern science, despite the fact that recently there has been an active development of this branch of knowledge.

The object of the research are terminological units that reflect the basic concepts of modern terminology in the field of clinical psychology.

The subject of the research are structural, morphological, syntactic and semantic features of the organization of the terminology of clinical psychology.

The purpose of the study is a comprehensive review of the terms of clinical psychology in various aspects: lexical-semantic, word-formative and cognitive.

The scientific novelty of the study lies in the fact that for the first time a complex study of the terminology of clinical psychology has been conducted, which enables the determination of the general and specific features of the formation of this terminology.

Research results. Exploring the problems of terminology at this stage of development of society appears to be the most important task of linguistics. In the modern world, terminology began to play a leading role in intercourse and communication, being a source of information, a tool for building up an expertise and even a mean of accelerating scientific and technological progress. Therefore, an expert or a specialist of any field acts as a carrier of a certain professional language, which he must master on a high level for an effective communication while exercising his professional activities.

Terminology is the most sensitive to external influences part of lexicon. The influence of society on language is the most clearly manifested in terminology. Considering that terminology is a separate branch of linguistics, there is an opinion among researchers that terminology as an independent scientific discipline developed gradually as a result of the autonomous evolution of individual scientific trends. According to MM. Volodina, the leading areas of terminology that we will be also considering in this paper are: methodological studies, theory of a term, philological studies of terminology, functional stylistic studies of terminology, diachronic studies of terminology, ordering and standardization of terminology, scientific and technical translation, professional linguodidactics and sectoral studies of terminology [1, p. 54].

At the moment, there is a large number of works in the field of linguistics that examine the concept of the term, its linguistic and semantic components as well as reveal the content of this concept (K.Y. Averbukh, L. Alekseyeva, O.S. Akhmanova, A. Baranov, F. Berezin, Y. Blokh, N. Vasilyeva, G.A. Vinokur, M.N. Volodina, B.N. Golovin, C.V. Grinev, V.P. Danilenko, A. Dianova, L.A. Kapanadze, R.Y. Kobrin, V.M. Leichik, D.S. Lotte, L.L. Nelyubin, P. Piotrovsky, N.V. Podolskaya, A.A. Refor- 
matsky, A.V. Superanskaya, V.A. Tatarinov, D.A. Khayutin, etc.). Modern terminological studies emphasize the complex structure of the term, which implies the multifacetedness of terminological analysis.

Doctor of Philological Studies V.D. Tabanakova attempted to answer the question why there is no generally accepted definition of the term: "On one hand, this is due to the fact that the theoretical foundations of terminology have not been sufficiently developed, its basic concepts are not differentiated and there is no common opinion what is a scientific and technical term. On the other hand, those various definitions that exist now in the literature do not always and do not fully reflect the essence of the phenomenon "[10, p.24]. According to observations of O.V. Superanskaya, N.V. Podolskaya and N.V. Vasilieva, the representatives of different disciplines associate the term with their own special concepts and representations, which has an uneven volume of content and is determined in its own way [9, p.11].

Today the most common definitions of the term are as follows:

- "A word or phrase that are denoting empirical or abstract objects, the meaning of which is refined within the framework of the scientific theory" [3, p. 709];

- "The word (or combination of words) is the officially accepted name of any concept in science, technology, art" $[8, \mathrm{p} .115]$

- "The most informative unit of natural language, the exact carrier of information about the scientific concept" [5, p. 19];

There are several approaches to the study of the term. Since the 1970s, the systematic approach becomes increasingly important; its intensive development was caused by the progress of the scientific and technological revolution and was also due to the fact that modern scientific knowledge has become more profound and complex, multilevel and multidimensional . These properties of scientific knowledge and needs of its development correspond to the main lines of development of the systematic approach.

Concepts and methods of systematic analysis are applied to the research and description of scientific and technical terminology. The lexical system of a language is a complex apparatus, which includes many subsystems that are distinguished by various characteristics (semantic, structural or functional). An important place among these subsystems is occupied by the terminology of various fields of knowledge. The systematic organization of terminology lies in the framework of the synthesis of logic and linguistic systematization. The correspondence of terminology to a system of interconnected concepts is conditioned by objective connections between subjects, processes, properties and represents a logical consistency.

By the end of the 20th century, studies devoted to the problems of terminology have moved to the new stage cognitive. This stage reflects the interest of researchers concentrated on the relationship between culture, national thought and speech.

The traditional connection between the terminological research and the cognitive sciences provided the basis for the active integration of the cognitive approach into terminology. It is considered expedient to examine terms from the cognitive point of view, considering that a cognitive research must necessarily take into account the fact that the language is an "encrypted" information regarding different types of thinking that correspond to different stages of human development. There is a need to take into account all types of information that are involved in the formation of a new knowledge. At the same time, special attention is dedicated not only to traditionally allocated types of knowledge, but also to the phenomena of horizontal and vertical measurement of social knowledge, as well as the scientific, professional and cultural memory of the term. Those terms used by experts in a particular field of knowledge are special cognitive structures. According to M.M. Volodina, it is important to identify which concepts (structure, content and degree of concreteness) are at the heart of the terminological nomination in a particular language and which contribute the most to fixing, storing and transferring scientific knowledge "[1, p.84].

For a linguist who conducts his research, the terminological nomination bears the imprint of the linguistic personality of the scientist and the concept to sphere of the language, thus representing not only a narrow professional knowledge, but also a knowledge about the world, including its cultural and historical aspects.

Coming back to the aim of our research, the terminology of clinical psychology, it is necessary to refer to the origins of the scientific clinical psychology, traced back to the end of the XIX century, when Wilhelm Wundt (* Wilhelm Wundt (August 16, 1832 - August 31, 1920, Leipzig) - a German physician, physiologist and psychologist.) founded the Institute of Experimental Psychology in Leipzig. Clinical psychology [Gr. Klinikê care for bedridden patients, treatment] is a field of psychology that studies the mental factors of the origin and course of diseases, the effect of disease on the personality, the psychological aspects of healing effects. The structure of clinical psychology includes pathopsychology, neuropsychology and somatopsychology, psychology of health and psychotherapy. In contrast to the definition given above, some authors understand clinical psychology as a section of medical psychology. [7, p.232]

In the modern national medicine and psychology, such terms as "clinical" and "medical" psychology are used the most often and understood as synonyms, although in a number of countries of the world, there is a delineation of these concepts between specialists. Therefore, the discussion about the correlation of clinical psychology and medical psychology cannot be considered complete yet.

For the terminology of clinical psychology, the following terms are considered to be the core ones: symptom, syndrome and complex. In this study we will analyze in detail insider the definition of the term "syndrome".

According to S.Y. Golovin, SYNDROME is a certain combination of signs of a particular phenomenon, united by a single mechanism of occurrence. Due to the general mechanism of appearance, they are combined in a consistent and regular way, characterizing a certain state of the organism. The term is used in pathopsychology, meaning a certain combination of signs of a disease "[2, p.423]. V.A. Zhmurov clarifies this term, defining it as a "cluster or group of symptoms, arising together and considered as indicators of a particular disease or disorder" [4, p.581].

In the terms of clinical psychology that have origins in the ancient mythology, there certain characters that prevail. In particular, the term "Persephone syndrome". 
The Persephone syndrome is a term indicating the clinical state of excessive emotional attachment that has arisen between mother and daughter; under condition of such an emotional attachment, they both develop a similar neurotic symptoms in case of their separation [2, p.457].

In Greek mythology, Persephone is Hades' wife (Pluto), who abducted her and carried her into his kingdom. Demeter sought her daughter all over the world, giving herself up to a deep sorrow and causing the barren land as nothing would grow on the sown fields. Once learning of the abduction, Demeter turned for help to Zeus with a demand to return Persephone. Hades let Persephone go, but before liberation he gave her seven grains (or three grains, as reported by Hermes) of a pomegranate. These grains of pomegranates originated from the drops of blood of Dionysus. Persephone, who all this time refused food, swallowed the grain - and thus was condemned to return to the kingdom of Hades. To reassure Demeter, Zeus decided that Persephone would spend twothirds of the year on Olympus, and one third in the kingdom of Hades, or (according to other sources) six months on Olympus, the other half a year in the kingdom of Hades.

Some sources provide that Persephone, during her stay on the Mount Olympus, ascended to heaven each morning becoming a constellation of the Virgin, so that Demeter could see her from everywhere. [6]

Another term in the language of clinical psychology is "Diogenes Syndrome":

The Diogenes syndrome is a mental disorder characterized by an extremely disparaging attitude towards oneself, social isolation, apathy, propensity to accumulate and collect all sorts of things (pathological accumulation) and lack of shame $[3,28]$.

The background of the term suggests that Diogenes, being an ancient Greek philosopher, arranged his habitation in a clay cask near the Athenian agora. He laughed at religious ceremonies, demagogues and he considered politicians to be sycophants. He declared himself a citizen of the world and propagandized the relativity of generally accepted norms of morality $[9,45]$.
Both terms explained above reflect the fusion of two cognitive spaces: mythological and psychological. They form, according to the theory of J. Fauconnier and M. Turner, a common cognitive space. Already the originator of the vocabulary of psychological terms S.Y. Golovin in his commentary on the dictionary's entry "Persephone Syndrome" notes a substantial inconsistency between the definition of the term and its onomastic component. Analyzing the structure of the term and the myth of Persephone, we note that the term embraced only the logical conclusion of the mythological narrative. More noticeable traces of the narrative, as well as the mythological image, are absent in the structure of the definition of this psychological term.

Conclusions. At present, there are different approaches to the analysis of system-structural, cognitive, comparative-historical terminology. In our study, we paid particular attention to the cognitive approach for the analysis of the suggested terms. By "term" we mean a word or sign unit that falls into a special field of a certain area of knowledge, becomes dependent on this field, is saturated with a special meaning and is used to convey professional information.

The terminology of clinical psychology, which has become the subject of this study, has generally interdisciplinary nature. The terms of mythological origin are included in the terminological systems of seven out of eleven directions of clinical psychology. Most of them are proper terms of clinical psychology. These terms are characterized as complex, showing special compositional semantics.

Having chosen the cognitive aspect of the study of the terms of clinical psychology, we have proven that using this method is not only possible to analyze the conceptual structure of the term and find traces of a mythological narrative or mythological image in it, but it is also possible to evaluate the success / failure of the term as custodian bearer of specific information maintained in clinical psychology by cultural knowledge in the form of knowledge of myths and fiction.

\section{REFERENCES}

1. Volodina M.N. The cognitive-information nature of the term (on the material of the terminology of the mass media). Moscow: Moscow. Uni-t, 2000. Issue. 2. 128 s.

2. Golovin S.Y. The dictionary of the psychologist-practice. Ed. 2nd, - Minsk: Harvest, 2001, - $971 \mathrm{~s}$

3. Gritsanov A.A. The newest philosophical dictionary. Moscow: Book House, 2003. 3rd ed. $1280 \mathrm{~s}$.

4. Zhmurov, VA A large explanatory dictionary of terms of psychiatry. - Elista: Djangar, 2010. - 864 s.

5. Kvitko I.S. The term in the scientific document. L .: Science, 1976. 127 p.

6. Myths of the peoples of the world. M., 1991-92. In 2 t. T.1. P.667

7. Psychology. Dictionary / Under total. Ed. AV Petrovsky, MG Yaroshevsky. - 2nd ed., Moscow: Politizdat, 1990. - $494 \mathrm{~s}$

8. Reformatsky A.A. Introduction to Linguistics. 5 th ed. Moscow: Aspect Press, 2007. 536 pp.

9. Superanska A.B., Podolskaya N.V., Vasilyeva N.V. General terminology: Questions of theory. Moscow: Librokom, 1989. $248 \mathrm{p}$.

10. Tabanakova V.D. The concept of the scientific and technical term and the requirements for its definition. Gorky: State University, 1982.

\section{Когнитивный аспект в изучении терминологии клинической психологии}

Т. И. Семикрас

Аннотация. В исследовании рассматриваются вопросы определения термина в научной литературе; анализируются соотношение термина с понятием и словом; указываются основные функции термина; изучаются современные подходы к изучению терминологии. Статья содержит анализ терминов клинической психологии.

Ключевые слова: термин, терминология, клиническая психология, эпоним, мифологизмы. 